\title{
Abigbo's Identity in Music Making and Repertory of Songs: The Mbaise People's Heritage
}

\author{
Justice Chukwudi Okoro \& Festus Goziem Okubor \\ http://dx.doi./org/10.4314/ujah.v21i2.9
}

\section{Abstract}

This paper directs attention to Abigbo, an outstanding traditional music of Mbaise people of Igbo south, east of the Niger. It gears to interrupt and challenge willful observations by western-oriented music lovers' derogatory opinion, contrary to music in traditional setting such as 'Abigbo'. To realize this objective and prove wrong the ill-informed critics, 'Abigbo's uniqueness in song rendition and peculiarity in music making is conspicuously examined here as a case study. The origin and development of Abigbo, its uses, and relationship with other aspects of Mbaise culture are discussed in this work. The musical challenges are highlighted with the dance formation, movements/steps and the ensembles costumed critically analyzed. All these are essentially adumbrated in association with music making trends in contemporary Mbaise. Equally reviewed where applicable are Abigbo's relevance and inevitable roles in achieving the goal of societal well being. Song communication supported with body language and phonic emission via vocals are equally matters of great interest here. Methods employed in the data collection are library source of information obtained from associated printed materials documented in the library shelves. The researcher consulted relevant ones, read through them during desk work, and use their extracts as backup information to the subject of discourse which he initiated. Few of the procured print media materials are equally paraphrased as and when due. Datum is also secured through participant observation. At this juncture, 
the researcher's sense of sight and aural perceptions are actively utilized along with retentive memory with the view to capturing the salient points needed for the paper. A few literature reviews that border round music making in rural culture are altogether, examined to guide and back up the thrust of this discourse. Abigbo has proved its worth beyond all reasonable doubt during its performance presentation in Mbaise social culture. The musicians' close attention to the masses, particularly the zealous ones who are inclined to get at African tribes' traditional music to subject them to western notation is a spring board to its fame. At this juncture, we resolve that for music making through song communication to logically reign supreme in Abigbo, its practice by interested artistes should be enhanced and encouraged even beyond the ensemble's environmental origin. This done helps to secure indigenous interest akin to norms and values within the fabric of Mbaise society.

Keywords: Mbaise, repertory of songs, Abigbo, music making, identity/heritage

\section{Introduction}

"Anthropology in its musical perspective theory places emphasis not so much on the structural components of music sound but on the parts music plays in culture and its functions in the wider social and cultural organization of man" (Merriam, 1964:4). The researcher, in consonance with Miriam's posture, conceptualizes Abigbo in this study from its - existential and normative values. That is, what Abigbo is in line with what are expected of it in Mbaise culture area, which typifies what Okafor and Emeka (2004:69) call "a geographical area occupied by people whose cultures exhibit a significant degree of dissimilarity with the 
culture of others." This is so because the music is rooted in Mbaise culture in both its composition and rendition for satirical reinforcement of indigenous values. The Mbaise people are humorous in behaviour when they make music. They move their bodies in total rapport with the music. At this junction the audience wails and howls as an expression of appreciation and encouragement. The popularity of Abigbo, especially for merriment has subsequently led to its usage by powers that be, leaders of thought and custodians of people in their social mobilization campaigns.

Central to the pseudo remarks made by ill-informed critics against music in African culture which include Abigbo are in the areas of musicianship, uses of music, music theory, music and language. Others are the people's musical style as it affects: rhythm, harmony/ polyphony, form as well as melody.

Musicianship: This is considered tribal which implies absence of music professionals, equal participation of everybody in music making and music homogeneity. These are considered not taking cognizance of many of the larger political units with complex music structure, trained musicians, royal patronage and music specific to a particular strata of society (Randel, 1986). Use of music: the notion that our traditional music is majorly entertainment-oriented is falsified. Though Africans conceive of it as entertainment, perform and listen for enjoyment, little work in African tradition is done without the rendition of appropriate music; few activities are properly carried out without appropriate music so said Randel (1986). Music Theory: despite the clam that there is little specifically musical terminology and no written theory in our traditional music, ideas about our musical structure are evident. The traditional music improviser is expected to go 
through a series of sections, each without specific characteristics, entitled preparation, beginning, basic pattern, development variations, successful completion, ending, and tail (Randel 1986). Music and Language: That the composition of our traditional vocal melodies may be limited by the pitch movement required in the text is a given. Nevertheless, the use of African traditional secret texts is related to the wide-spread use of music as a form of protest. This practice was eventually used as form of protest against Europian domination and appears to have played a role in the development of afro America music as well (Randel 1986).

Rhythm: while we accept that in our traditional music, non-metric music exists, ... The vast majority of styles is subject to strict application of duple, triple, and compound duple meters. The accompaniment of singing with hand clapping provides simple, unified structure. Instrumental performance involves the interaction of independent lines within a governing matrix known as poly rhythm (Randel, 1986). Harmony and Polyphony: Evidently there exist contrastive and complex sounds arising from varieties of timbres and the extra-ordinary singer's vocal effect in combination with instrumentation. However, Randel (1986:19) offers that

The intervallic relationship of the voices is strictly regulated, with thirds most common, forth's and fifths also found, second and sevenths rare. The structuring devices of polyphonic music are initiation sometimes resulting in canons; parallelism, sometimes with suspensions, overlapping hockets performed by series flutes or horns each playing one tone; antiphonal or responsorial technique in which the voices overlap; and heterophony, in which 
each of a number of instruments simultaneously performs variations of a basic theme.

Form: Preservation of complex traditional music materials in a basically dualistic structure is also wide spread. It is observed as though it were a fiasco in the people's music making. "This Characteristic form is based on a short line or pair of lines repeated and varied many times. An underlying rhythmic cycle with an accompanying melody is the basic unit, several renditions of which may make up a section of a piece that is thus replaced by a new one. In performance, the length and rhythmic melodic essence of the line remains constant, but the improvised variations and the number of repetitions change (Randel, 1986).

Melody: Another consensus holds that the typical contour of our traditional melodic line is mildly but not sharply descending. This is so because, vocal style and timbre in Africa are most often relatively relaxed, with considerable rasp, but full, round tone. Men and women sing differently, the women using more nasality, less vocal width, and high tessitura (Randel, 1986). It is noteworthy to conclude that Abigbo being an integral part of traditional black African music is identified with the aforesaid inherent, concomitant musical values. These are visible in the body of the work where applicable.

\section{Geographical Location of Mbaise}

It is bounded in the South by Azaraegbelu pocket of villagers in Emekuku town, along Owerri - Umuahia road; in the East by Imo airport/Ngor Okpala L.G.A. towards Aba senatorial district; in the North by Obowu L.G.A. towards Imo River; in the West by Ikeduru L.G.A. towards Okigwe. According to oral history, 
Mbaise is one of the most densely populated mono-cultural societies in Africa (Lawal, 1997; Nkemneme, 2009). Its vegetation is typically but not exclusively virgin perennial forest with economic trees such as: Raffia palm, Iroko, Mahogany, Ebony, Obeche, Wallnut, Breadfruit, Star apple, oil bean, etc. The soil is highly humus and favourable to agricultural activities.

Social Culture: Mbaise became a political entity in 1914, following the amalgamation of its clans namely: Ahiara, Agbaja, Ekwereazu, Ezinihite and Okeuvuru. Each Mbaise autonomous community is composed of villages with one traditional ruler customarily called Eze. Every village has a constituted authority whose primary concern is raising the quality of life of the citizenry. Amucha (2009:110) explains that - "In each local government area, each village organizes village meetings and when all the village meetings (Association) in one locality called a 'town' come together to form one common meeting for the town, a town union is born". Among the Mbaise, kingship as that of the Igbo, is based on the Umunna, Nnamochie or Ikwunne. While the Umunna is the paternal lineage, the dominant social organization in Igboland, the Nnamochie or Ikwunne is the maternal affiliations. Generally, the Umunna membership association and traditional title taking such as NzelOke Nze, Eze (Royal fatherhood), Duru/lolo, occupy a pride of place in promoting egalitarianism, dialogue and communalism. The titular institution encourages individualism and accords respects to those in positions of authority. The Aladimma, made up of heads of kindreds and local vigilantes, the judicial arm of each village, is charged with adjudicating on minor issues while major ones having to do with justice and equity are referred to village/traditional council of customary red caps chiefs. 
Economy: As a predominantly agrarian society, Mbaise is economically known to produce farm products such as assorted tubers (three - leaf yam, yams, coco yam, cassava) kernel and palm oil. These are responsible for the preponderance of village markets in Mbaise where they convene on alternative four days in order to market their articles of trade. Their major markets are: Eke Itu, Eke Nguru; Orienta Chokoneze, Orie Mbaise, Orie Uvuru; Afor Enyiogwugwu, Afor Oru, Afor Ogbe, Afor Ajaala; Nkwo Mbaise, Nkwo Lagwa, Nkwo Ogwu and Nkwoala Umu - okirika. To this end, Nneji (2009:228) throws more light to this as he affirms: "Apart from agricultural products, local craftmen and blacksmiths also brought their products such as matchets, mortar and pestle, pots and ropes fabricated locally to the village markets for sale. They in turn use their proceeds to buy their needs from other sellers, in an environment where the buyer and the seller are in close contact". Likewise, Mbaise is endowed with abundant Raw Materials that can be transformed to sustain industrial manufacturing. These natural resources are harnessed for both domestic and foreign usage such as stated: Maize - Feed, cornflakes, glucose, starch, floor, etc.; Livestock - Blood meat, fat for food processing, manure and bio-gas, meat canning; Palm wine/Palm tree - Basket, bags, household crafts, (roofing mats), alcoholic drinks, bottled palm wine, yeast, fire wood; Yam/Cocoyam - Consumed as food, animal feed, glucose, starch, flavor; Cassava - Vegetable, food thickener (when processed), flour, industrial starch; Palm oil - Lubricating oil, grease, cosmetics, soap; margarine, used for frying and cooking food and Bread fruit - Oil floor, food.

Against all odds, Mbaise people, so to speak, embark on long distance trade at times. This include such places as - Okigwe where they purchase salt for domestic market, Etchee to buy 
cassava and garri, Yenogoa, Ohaji, Egbema, Oguta for snails and bush meats; Ikwere to buy sea creatures or pices like crabs, crayfish, cod, etc. Any other places of convenience the traders are found there for business transactions of goods, commodities and, of course, services. Such trips are mainly done in group not only through automobiles but equally on their respective bicycles or alternatively on foot as the case may be. Banking which provides impetus to trade development is well established in Mbaise with branches of major banks like Union Bank PLC, UBA PLC and a host of Community Banks are in operation to facilitate business transactions with loans offered at intervals. All these would not have been possible at their level of operation if indigenes were not regularly checked by Abigbo village spies or news agents who forward their reports to the ensemble songs composers for public announcement. Nobody wants to be spotted out as an idler in the community.

Songs: As an autonomous genre of musical expression, song dates back to the very genesis of Christian era with its root more or less in folksongs. Glenon's (1980:164) definition considers a song as "relatively short composition in which poetry and music are combined". "Many of our social comments, moral codes and guide are couched in music and songs" (Okafor,2005b:6-7). "The songs have the power to communicate reflectively to all members of the audience, whether they are directed to individuals or not. Even the ones directed to individuals possess instruction and verdict, that each member of the audience draws a lesson from, as applicable to him/her within context" (Idamoyibo, 2010:216). They are products of human vocal music as opposed to instrumentally emitted sound. Almost all songs have words, whether they are actually sung or not, so that when a song is 
played on a musical instrument, words are automatically conceptualized, though they may not be verbalized. This fact on acoustic variety is evident in the strings, where striking with a spectrum as against rubbing with a bow or plucking with fingers could differentiate tone-colours.

Throwing more light to the definition of song, as vocal music, Harvard Music Dictionary (Randel, 1986:768) affirms: "Song is a form of musical expression in which the human voice has the principal role and is the carrier of a text; as a generic term, any music that is sung more generally, a short, simple vocal composition consisting of melody and verb text." Songs have been defined in several other ways with some confusions arising out of the meaning. The form and style of songs reflect the social structure of the people. The repertory is chiefly homogenous, save that special sub-styles are later developed for certain categories of songs. The context together with the language is elusive to the non indigenous audience. Songs well sung can urge listeners to passion and exasperation; beyond that they can inspire onlookers to dance. Words expressed in songs define the total human idiosyncrasy: his religion, social and political belief. Song are functionally of great poetry in Abigbo, just as the historical poems of the Ijala musicians of Yoruba tells of great feat achieved by their prominent hunters.

Song Text: Text of a song on the other hand, is the words to which music is set. Pitch is essentially its element. Musical text is likened to a major vehicle for self expression, a regulator of social and interpersonal behaviour, and of course, a mark of group identity. The text reveals a great deal about societal attitudes, the social behaviour they admire, hate or take for granted. At times the text is philosophical, humorous, saucy, obscene, proverbial, contemptuous and divisive or ridiculous. More impact is made 
through the text rather than melodies. Nketia (1975:195) while discussing and evaluating song texts in the context of their usefulness writes among other things - “... songs based on the use of allusions and poetic images conceived in the style of proverbs, or songs which exploits the evocative power of names and bynames. ...may be reflective, or philosophical, sentimental or satirical, humoring or comic: ... It may be intended to entertain, inform, praise, insult, exhort, warm or inspire their audience or perform similar function.” More so, Merriam (1964:205) observes that: "expression of general cultural values revealed in song texts can be carried further to a study of the underlying psychological set of; ethos' of a particular culture". The text makes provision for the mental expression of the tune, which subsequently develops the contextual emotional values. Hence, as the tune keeps going in consonance with the speech tone, while proceeding, the textual progression resultantly operates under its direction, in different conditions of the musical tune.

Song Themes: Abigbo textual themes are not unlike those of Celestine Ukwu, which Okafor (1999:115) identifies thus:

quite varied, praise, admonish, an observer; and a critic. Message bearers, preachers, and point at the way people should follow... therefore more than entertainers but faithful witnesses of society. The gap between the rich and the poor, the relationship between leaders and followers, brotherly love, peace, patience, man-woman palaver, optimism, social ills and death are some of the persistent themes of the music.

Abigbo vocals comprise the soloist and chorus. Although the soloist dominates the chorus at times, still a balance between 
the two prevails. The vocal section is more important than the rhythmic background. Arising from this, the instrumentalists guide against overshadowing the vocal parts. For instance, one of Abigbo's entertainment songs starts with introductory solo and vocal recitative recited a cappella in a moderate tempo. The instrumental accompaniments and chorus responses are alternated with the leading voice. At the cadential point, the soloist begins to recite his line loud and fast without chorus accompanying it, save the instrumentalists only. As a rule each song text, to a large extent, is sung by a soloist, followed by the chorus before instrumental accompaniments follow suit. In Abigbo cadence points, the chorus usually withdraws for the leading voice to usher in solo-chorus dialogue, which is at times supported by instruments to round-off the music loud and fast. The soloist recites his vocal verse backed up by another occasional solo voice from the chorus. This is witnessed in the songs after the whistle is blown to introduce improvisation of the music at faster tempo. The periodic soloist's voice from chorus seizes prior to the postlude leading to the last leading voice verse. This instance also prevails in the songs after the first and the third solo verses respectively. Lengthy vocal rest usually leads to instrumental dialogue with adept display of improvisation/ extemporisation punctuated with a follow-up Abigbo song paraphrases and neologisms. Thus, the soloist/chorus/instrumental rendition interrelationship summarily yields this result: each soloist verse (including spoken monologue) identified with amusement traits, in most cases, concludes with a continually repeated chorus stanza or recurrent refrain after every instrumental interlude. This is the case in abigbo song captioned: Chokoneze ndi nwe egwu (Chokoneze the Owner of Abigbo). 
Abigbo: The traditional ensemble called Abigbo is made up of young men between 40 and 50 years of ages. They are not formally educated, and autonomous in economic life such as trade in clothe, fish, garri, palm oil and kernel. Their trades make them spend much time on the road, though they travel no great distances by modern standard. Abigbo has a measure of emancipation which derives from travelling, and the independence to say things as they see them. As the artistes return to their locality daily or after trading ventures of a maximum duration of three days, they still have a firm identity of their values. The result is a robust mentality which appears in their songs and principally, in the way the very songs are presented to the community.

Their performance is important, both as an accompaniment to the songs and even in the very order in which the songs are presented. The spirit has to be on the ascendant for certain songs to be performed. On a given occasion, the ensemble refused to perform because the music was not yet properly rehearsed. It had not reached the apogee of excitement which would liberate the spirit and body to perform their right. When the music was later performed, the artistes were justifiably appreciated. The audience was completely overwhelmed with bliss as they were thoroughly immersed in the mood of the song. Most often the ensemble will progressively move from general statement to public topics, and later to personal satire. By the time the group arrives at the personal satirical songs, the singers/dancers are thoroughly warmed up while the audience is in the mood of absolute excitement. In this case, one will likely hear reactions like Ohitiela (it has heated up) and "Akwasa" (beautiful). Whenever the music is in progress, the performers and audience are magnificiently unrestrained. Through the medium of Abigbo, the 
indigenes learn existing politics in their community; through this same avenue they express their emotion towards their leaders.

\section{Abigbo Dance}

In Africa, the nature of music is influenced by the activities with which it is associated. Abigbo as an entertainment music invariably spreads information, adulates heroes/heroines among others. Greater attention is therefore paid to the message covered by the music than that of the dance. The dance movements and steps are not intricate to enable the dancers sing effectively and also considering adulthood of the dancers. While the music stimulates emotion, the dance contrarily releases it. The dancer dress in white singlet upon George wrappers, with two scarves tied round their wastes.

The dance formation is semicircular with the instrumentalists seated at the centre. The style could be either stylized or medley; it all depends on the choreographer, and of course, event situation. The dancers outward and inward facings are not rigidly observed nevertheless, all of them dance to the same rhythm, melorhythm. The body part generally emphasized is the waist shaken according to the tempo, which may be conditionally fast or slow. Footwork accompanies shaking of the west. Each dancer chooses a particular instrument which he dances to its sound effect. The footwork synchronizes with the time liner instruments (Ogene and mgbirigba). The right foot moves forward on a beat followed by the left foot motion on the corresponding beat. The dance is relatively slow compared to other Mbaise dances such as Digwu, Alija and Ngelenge. The audience who are inspired by the ineluctable music can participate in the dance by dint of spontaneity. 
The dance usually starts sequel to the instrumental entry. All the dancers are well informed on the coda for rounding off dance, which is usually initiated by the master drummer. Both instrumental accompaniment and dance stop simultaneously. The dancers countenance convey their emotions of bliss at its ecstasy and show that the music itself is really entertainment-oriented.

Abigbo expresses dissatisfaction with leaders for extracting money from the poor in the guise that it is for community development. Through Abigbo songs husbands are informed how their wives trick them and indulge in extra-marital relationship. The musicians are routinely gorgeously dressed with "george" loin cloths and white long sleeve shirt on top. They also have long stripes of cloth which are the same material as their loin cloths, tied around their heads across the foreheads. In their hands are held locally made fans or handkerchiefs depending on their choice for a particular performance outing.

\section{Functions of Abigbo in Mbaise Infrastructural and Social Development}

The researcher's idea of musical function in the context of Mbaise local tradition means music that emanated from her rural areas (as against that which evolves in urban centers or cities) and serves as a corporate agent of communal development. Radcliffe (1952) whose theoretical orientation closely connects with the concept of 'function' in modern anthropology stresses its usage with emphatic application to the social system. According to him, as recorded in Merriam (1964:211)

Function is the contribution which a particular activity makes to the total activity of which it is a part. The 'Function' of a particular social usage is the contribution it makes to the total social life as the "functioning" of the total social system. It is a 
condition in which all parts of the social system work together with a sufficient degree of harmony or internal consistency, without producing persistent conflicts which can neither be resolved nor regulated.

This view implies that a social system has a certain kind of unity, which we may speak of as a functional unity. Functionally, "African music is human intent expressed into action either to communicate ideas, portray culture, symbolize event, socialize people, stimulate emotion, and related functions. They are manifested in performance techniques and individual styles-social and instrumental-voice textures, choice and use of traditional repertoire and so forth" (Ibekwe, 2010:34). Abigbo is not left out in this conclusive remark. Certainly through unique, authentic and manifold performance behaviours, musical roles in Abigbo are made manifestable.

Abigbo works hand in hand with the town union. Survival and greatness in Mbaise is laid in the conceptual and practical reality of fraternity, unity and co - operation between Abigbo and the town union. The institutional idea of Eji esi na ulo mara mma puta ama (charity begins at home); Igwe bu ike (Unity is Strength); Onye aghala nwanneya (be your siblings keeper); among others safeguard the ensemble's mental preparedness for team work with the said union. That a few of the pioneer graduates in Mbaise were sponsored through community effort is made possible by Town Unions such as: Itu Ezinihite Community Development Association; Enyiogugu Welfare and Development Union; Amuzu Progressive Union; Uvuru Development Union. This was achieved in conjunction with Abigbo's songs of encouragement for patriotism and excellence. With these names so - mentioned, one can deduce that they perform in the community what their nomenclatures suggest. 
One of the ensemble's songs basically gears towards the advancement of social development by acknowledging Mbaise indigenes in all walks of life, who through their respective businesses contribute (in one way or the other) to the welfare of the society both at home and elsewhere they sojourn. As the soloist recounts their achievements one by one, the chorus concludes by wishing them anointed hands coupled with divine grace, mercy and favour. Abigbo embarks on infrastructural development roles with salient aim to discourage idlers by constructively castigating them through songs. By so-doing, the ensemble develops the basic structures that model decent citizenry and a habitable social environment for both present and on-coming generations. For the benefit of the doubt, the song extracts below buttress our point beyond reasonable doubt.

\section{Igbo Text:}

O.A.E.: Ekpere ekpewere uтu-Igbo nde gbawa ahia

N.N.E.: Aka nchawa, Chukwu mere anyi ebere nye umu anya aka nchawa/ngozi. NB: This chorus is repeated after every solo line and a voice from the chorus up to a certain extent.

\section{O.A.E.: Ngozi inyewe umu Igbo ebe nile}

Chorus: ... .

„: Igwe nde gbawa okada ebenile

„: Nde rugha n'office ebenile

„: : Igwe nde shoe maker anyi nwere enwe

, : Nde rugha carpenter ebenile

, : Nde rugha okuga ebenile

, : Ma nde tewe na ngwo n'ete nkwu

, : Ndi Musicians anyi nwere

*(A voice from the chorus) Batu electronics no nime Aba, *A voice from chorus - Eze Fredrick Uzoma, nwokoma enyi oha Owu aka n'ere jorgi di n'ime Aba 
*A voice from chorus - Chief Uwasinga onye ulo anyi-o! ," Owu a chemical merchant, onye ukwu ama-ama n'Aba East of the Niger

O.A.E.: Onye Chogha ebe ano n'eri ego yee!

Onye ahu bia me gosi ya ulo no nime Aba

„: City Global Hotel no nime Aba,

„, : A gam ije ebe ahu je rie ego-o!

, : A gam ije ebe ahu je hie ura-o!

O.A.E.: Echetele $m$ Goodman Nwa onwukwe-e! ...

*A voice from chorus - Aka dimma n'aru ulo di na Portharcourt Company Ltd.

O.A.E.: Dr Benjamin Nwa Onwukwee, aka n'eji agwo oria no nime Abaa;

*A voice from chorus - $O$ wu oji akprogwu na akwukwo agwo. $O$ wu Akpochaa aha ya-agwoo,

\section{English Translation:}

Solo: Prayer prayed for indigenous Igbo businessmen.

Chorus: Anointed hands, God have mercy and give our children blessed hands. . . NB: This chorus is alternatively sung after each line of the soloist's leading voice up to a certain extent.

Solo: Divine blessing given to Igbo indigenes in the diaspora

Chorus: ... .

„: A majority of okada riders everywhere.

,$:$ All office workers everywhere

„: The majority of cobblers we have.

„: All professional carpenters everywhere.

„: All iron mongers everywhere

„: Including those climbing raffia palm tree and palm tree ...

„: The musicians we have 
*A voice from the chorus - Batu electronics in Aba. King Fredrick Uzoma, a goodman and public friend. He is a georji wrapper dealer in Aba.

Solo: Chief Uwasinga, a native of our community.

„: He is a chemical merchant; a well-known person in Aba,

East of the Niger

„: Anyone who yearns for where money is being squandered $-\mathrm{o}$ !

„: The person should come I will show him a house in Aba.. . .

„: : City Global Hotel in Aba! Abigbo ensemble, my people $-\mathrm{o}$ !

„: I shall go there to squander money I shall go there

to sleep $-\mathrm{o}$ !

„: I have remembered goodman, Onwukwe's son

*A voice from chorus -Good hand that builds house in PortHarcourt, Company Ltd.

*A soloist continues - Dr. Benjamin Onwukwe's son, \|:A herbalist doctor in Aba:\|

*A voice from chorus - He heals with roots and leaves. He heals after the patience narrates the problem.

\section{Abigbo Music Instrumentation}

Although the ensemble's tunable instruments are not tuned to the same scale, the artistes know the right pitch for each of the instruments. Care is therefore taken in choice of instruments, especially the Conga drums. In keeping with that, instrumentalists beat their respective instruments one by one and listen to their individual tones. Such comments as Uda ya adighi mma (the tone is not good), or $O$ di ala (the tone is low) could be heard where applicable. 
Idiophones: Ekere (slit drum), one of the musical instruments used in Abigbo, belong to the same family of auto-phone which includeekwe, Uhie, and Ikoro. It is the smallest (with higher pitch) of all the slit drums available in the ensemble. In constructing it, a slit is made on a piece of soft wood of the oil bean type. The wood is hollowed out to create a resonator. Thereafter it is left to dry. A finished product is between 7 and 9 inches or $(17.78-22.86 \mathrm{~cm})$ long. The highest tone is obtained by striking very close to the slit. The pitch is about $\mathrm{G}$ in the one line octave. Ekere is also used in other instrumental ensembles like diegwu, ekeremgba, okonko, where it plays the role of a soloist. Extra-musically, it features in evoking ancestral spirits.

Ogele (miniature clapperless bell) is a hollow tone oval rim meter frame instrument constructed by blacksmiths. It varies in size, while some are pared. In Abigbo music a medium sized single ogele of about $30.72 \mathrm{~cm}(1 \mathrm{ft})$ in length is used. It has a sonorous tone hence one with a nice voice is said to have ogele tone. The ogele functions as a metronome instrument in Abigbo music. Apart from its usage in ensembles, it also accompanies choristers in churches. Its extra-musical function includes drinking from it in order to be cured from stammer. Town criers use it to draw villager's attention; divines use it to evoke the gods. Ogele is not gender discriminatory in musical rendition. Its pitch in Abigbo music is about ' $\mathrm{B}$ ' in one line octave.

Mgbirigba: This school bell-like instrument functions in Abigbo as a metronome. The clapper is suspended inside the hollow and produces ringing tone when held at the base and shaken latitudinal. Its pitch in Abigbo music is approximately ' $\mathrm{B}$ ' in one line octave. The clapper bell is not only used in Abigbo but also in other 
instrumental ensembles like ekpe and okonko music. In meetings, the instrument is used to draw participants' attention.

Osha: This calabash, pod or basket hollow maracas is woven into goblet shape with akwara extracted from raffia palm tree decayed wooding body. The hollow space is filled with some pebbles, while the base is sealed with calabash wood. The sound is emitted by shaking the internal pebbles to produce ratting sound. Osha is commonly used in music making among women traditional music and dance. They use it together with $U d u$ (musical pot) and ogele to support child birth songs. No taboos are attached to all the instruments discussed. They could be handled by anybody and lent out at request.

The Membranophone: The varieties of membranophone are generally called drums and are the most important aspect of almost all instrumental ensembles in Mbaise where Abigbo originated. They are used in ekeremgba, Ese, ukom and agbachaaekurunwa music among others. Akpukpo gbada (antelope skin) preferably the female is used to brace Abigbo conga drums because of its tough and elastic skin durability as well as accessibility. The cone-shaped wood of the conga drums is constructed with such soft species of wood as agalaba ugba (oil bean bough). The membrane is stretched over the brother end of the wooden surface towards the rim edge while the opposite end is left open. The membrane tied to the wood with a string is strongly fitted with the aid of small pegs fixed round the drums radius. To tone the drums, the pegs are hit with sticks or stones whenever the tone is lower than required. This done activates the membrane, and subsequently raises the tone accordingly. Alternatively, the drums are placed under the sun to regulate its elasticity. If the tone is too high, water is sprinkled on 
the membrane to lower the pitch. The three-in-one drums: Oke $n k w a$, otiti ukwa and nne nkwa (male, medium and female tones) used in Abigbo ensemble are specifically constructed for it. Although their names may be the same with those used in other ensembles, the tones are quite different. E.g. the nne nkwa used in Agbachaaekurunwa is smaller and therefore has a higher pitch than that used in Abigbo. The other two drums: oke nkwa and etite $u k w a$ are always tuned from the master drum nne nkwa before a performance ensues. Such comments as $O$ damaana (the tone is now alright), indicates that formally drumming can now follow suit. The proximate pitches and ranges of the three drums are:

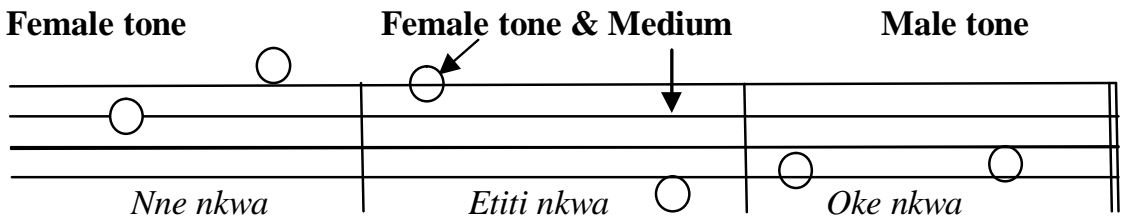

Fig.1: Abigbo Conga Drums Tonal Range

The lower notes are obtained by striking the centre, while the higher ones are derived from the rims. Of all the three drums, oke $n k w a$ is the smallest and highest in pitch. It is about $35.56 \mathrm{~cm}$ (14ins) long and $12.07 \mathrm{~cm}$ (5ins) in diameter. The drums are beaten with the fingers of both hands. The etite nkwa (middle tone) implies, it is the medium sized of the ensembles three drums. Its player's manipulating position and drumming technique are the same with that of okenkwa. Etite nkwa is about $40.64 \mathrm{~cm}$ (16ins) long and $17.78 \mathrm{~cm}$ (7inches) in diameter.

Nne nkwa, regarded as the master drum, is the biggest and produces the lowest tones. it is about $91.44 \mathrm{~cm}$ (3ft) long and $22.86 \mathrm{~cm}$ (9inches) in diameter. The player sits astride on the 
wooden part of the instrument. He then beats the drum with fists and occasionally with palms. Apart from nne nkwa, which yields rhythmic variations, all other instruments plays obstinate technique.

\section{Performance Occasions and Popular Patronage Facilitators in Abigbo}

In so many aspects of ethnic life, musical ceremonies performed witness limited audience due to their tribal base. Besides, a majority of the youths are not conversant with such genre of music. Rather, "they prefer the Western influenced inter-tribal music" (Edet, 1962:111). It is in view of this fact that in Abigbo - context of performance, venue, time factor, season, weather condition, rendition repertoire, publicity, etc. are, nowadays given all deserved attentions despite all odds. Doing so has reliably sustained the identity of relatively large size audience that has routinely graced Abigbo performance presentation not only with their presence but in cash and kind. Audience's degree of interaction with Abigbo artistes is very cordial and intimately related as observant-participants. The social strength is made up of peer groups from all walks of life; this includes both masculine and feminine gender ranging from teenage to adulthood resident within and outside the community.

Some of their public entertainment performances that attract the aforementioned humanitarians are witnessed mainly on the occasion of such social events as government award of scholarship to bright and indigent pupils and students of government owned study centres; tertiary institutional awards of prizes to the best performed students/schools; academic motivational lectures for students and workshops organized for both head teachers and principals in Mbaise; distribution of 
exercise and textbooks as well as computers to local schools within the five clans of Mbaise community; inauguration of business trustees and launching for project endowment. Establishment of Mbaise E-learning centres, equipping the school laboratory, funding of school library complex/equipping them with books and renovation of schools on the verge of dilapidation, which took place between $14^{\text {th }}$ August 2003 and August 2010 era of flagging off Back to School Programme, witnessed performance presentation of Abigbo. With the aforementioned continual financial supports coupled with regular musical performance invitations, Abigbo has all this while forged ahead as a living art in Mbaise.

However, the musicians use the ample opportunity (of their performance occasions for patronage) to boast of what they are capable of doing as adept musicians. Hence, they beckon on the listening audience to judge if there is any music album they have listened to that is better than Abigbo. Their additional intent is to achieve economic goal through self advertisement and to attract the attention of the onlookers to market their products during the life performance.

\section{Conclusion}

Abigbo functions as a local social medium for sanitizing social ills with constructive criticisms meted against the erring members of the society. It controls malefactors with apt message of amendments to ill conducts. It serves as a process by which social culture is tolerated and extolled, while vices are refuted and shunned. Abigbo musicians have noticeably measured up in maintaining performance quality and standard compositional technique. This, in effect, provides effective apprenticeship for the tyros, with the view to enhancing their expertise. Thus, it stands to 
reason that Abigbo Mbaise is rooted and oriented towards the positive continuity of those essential features which establish its 'utilitarian' purpose; and this, the composer/performer - producer should bear in mind. The relaxation obtained in its performance is indispensable for a healthy living.

We therefore make bold to conclude that abigbo be given due attention across global cultures with the view to sustaining the ensemble's continuity beyond its place of origin. Some ways of achieving this substance include: paying attention to the musical sound effect, singing style, instruments, formal structure, melody, rhythm and polyphony. This work is also a step in the right direction in achieving this set objective, hoping that further investigation (by someone else) be carried out in the nearest future to complement our effort on this subject matter.

\author{
Justice Chukwudi Okoro \\ Department of Music, \\ Delta State University, Abraka \\ Delta State, Nigeria \\ chuksjevang@gmail.com \\ \&
}

Festus Goziem Okubor

etiewututu@gmail.com

\title{
References
}

Amucha, L. C. (2009). 'The role of town unions in the development of Mbaise' in A. Nkemneme \& A. Anyanwu (Ed.) Towards Greater Mbaise. Lagos: Clean Foundation Resource Centre.110 - 115.

Edet, E. M. (1962 ). Music in Nigeria.Africa Music Society Journal,. 3, 111 - 113. 
Glenon, J. (1980). Understanding Music. London: Macmillan London Ltd.

Ibekwe, E.U. (2010). Music and the Philosophical Dimension of African Man. D. C. C. Agu (Ed.) Awka Journal of Research in Music and the Arts (A.J.R.M.A.), 7, $22-32$.

Idamoyibo, I. O. (2010). History, theory and philosophy of Okpe Igoru music: Compositional technique in African music. Germany: VDM Verlag Muller Gmblf and Co.

Merriam, A.P. (1964). The Anthropology of Music. Evanston: North Western University Press.

Nketia, J.H.K. (1975). The Music of Africa. London: Mgbo Publications Limited.

Nneji, F. (2009). Commerce and Industry in Mbaise: An overview A. Nkemneme \& A. Anyanwu (Ed.) Towards Greater Mbaise. Lagos: Clean Foundation Resource Centre. 227 232.

Okafor, R.C. (1999). The Life and Works of Celestine Ukwu. Enugu: New Generations Books.

Okafor, R.C. (2005). Music in a Technological University. Enugu: New Generation Books.

Okafor, R.C. \& Emeka, L.N. (2004). Nigerian Peoples and Culture. Enugu: New Generation Books.

Randel, D.M. (1986). The New Harvard Dictionary of Music. Cambridge: The Belknap Press of Harvard University. 